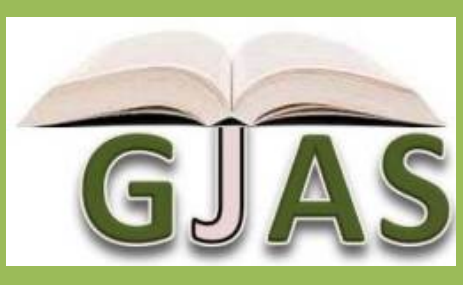

Research Article

\title{
Genetic Diversity of Cassava (Manihot esculenta Crantz) Genotypes in Ethiopia
}

\section{Tewodros Mulualem ${ }^{1 \star}$ Getachew WeldeMichael ${ }^{1}$, Tadesse Benti ${ }^{1}$ and Tesfaye Walle ${ }^{2}$}

\author{
${ }^{1}$ Jimma Agricultural Research Centre, Jimma, P.O. Box 192, Ethiopia. \\ ${ }^{2}$ Wolkite University, Wolkite, Ethiopia.
}

Article No.: 061013658

DOI: 10.15580/GJAS.2013.9.061013658

Submitted: 10/06/2013

Accepted: 22/09/2013

Published: 29/09/2013

${ }^{*}$ Corresponding Author

Tewodros Mulualem

E-mail: tewodros74@yahoo.com

Keywords:

Genetic diversity, cassava, variability
The experiment was conducted at Jimma Agricultural Research Centre. The objective of the experiment was to evaluate the genetic diversity of cassava using agronomic traits so as to characterize and cluster with in collected cassava genotypes. Thirty five cassava genotypes were sampled from the collection. Relatively high broad sense heritability was observed for plant height (42.08) and root diameter (31.88) indicating the existence of possibility for selection of genotypes for high fresh tuber weight. The clustering of genotypes based on 11 quantitative traits revealed the existence of five distinct groups. The maximum inter cluster distance was observed between genotypes under cluster II and V and I and V, hence, the genotypes grouped in these clusters could be used for crossing if high fresh tuber yield genotypes are planned in breeding program. 


\section{INTRODUCTION}

Cassava (Manihot esculenta Crantz) is one of staple food crop for millions of people who live in the world [1]. It is particularly important for food security since many tropical areas often experience unfavourable environmental conditions [2]. It is originated in the tropical Latin America [3] and was first introduced to Ethiopia by the British. After introduction, the crop has been found to have an excellent adaptation and growth performance in different agro-ecologies with productivity variation [4] which is by far greater than the global average tuber yield of $46 \mathrm{t} / \mathrm{ha}$ [5].

Although reliable statistical information on the distribution and production of cassava in Ethiopia is lacking, the crop has been cultivated, particularly, in the South, South West, and Western parts. Its use as a potential food crop in Ethiopia has increased during and after the 1984 famine [6 and 4]. The most important feature of cassava is its adaptability and produce reasonable amounts of yield in different areas especially on tropical environments and it often grows where most other crops fail [7]. In south and south-western parts, there are huge amounts cassava genotypes are distributed across diverse agro-geographical areas that have not been properly evaluated before [3] and their attribute remains unknown by breeders [8]. So, detailed descriptions of genotypes based on agronomical characters have tremendous impact on the conservation and genetic diversity of the crop. The present study, therefore, intended to evaluate the genetic diversity of cassava using agronomic traits so as to characterize and cluster with in collected genotypes for further breeding works.

\section{MATERIALS AND METHODS}

\subsection{Description of the Study Area}

The experiment was conducted at Jimma Agricultural Research Center located $366 \mathrm{~km}$ south west of Addis Ababa situated at latitude $7^{\circ} 46^{\prime} \mathrm{N}$ and longitude $36^{\circ} \mathrm{E}$ having an altitude of 1753 m.a.s.l. The soil of the study area is Eutric Nitosole with a pH of 5.3 that receives mean annual rainfall of $1432 \mathrm{~mm}$ with maximum and minimum temperature of $29.2^{\circ} \mathrm{C}$ and of $8.90^{\circ} \mathrm{C}$, in 2010/11 growing seasons. These environmental conditions are conducive for production of cassava [1].

\subsection{The Genotypes Evaluated}

Thirty five genotypes of cassava were considered in this study. The genotypes were collected from south, west and south-western parts of Ethiopia, during 2004-2008 cropping seasons. The collections covered diverse agroecologies with an altitude range of 1170-1940 m. a.s.l, representing one of the major cassava production areas in the country.

\subsection{Experimental Materials and Design}

The experiment was laid in RCBD with three replications on spaced $1 \mathrm{~m} \times 1 \mathrm{~m}$ and provided all agronomic practices as needed on growing period. Cuttings with 25$30 \mathrm{~cm}$ from 12 months aged cassava mother plants were used as a planting material on a ridge during onset of rainy season (early April). One month after planting, after the crop was well established, the plants were earthed up. Cultivation and weeding were carried out when necessary. The crop was harvested at 18 months after planting.

\subsection{Data Collection}

All the data were collected 18 months after planting as it have been suggested by [9]. Accordingly, data on plant height $(\mathrm{cm})$, number of main stem/plant, number of branch/plant, average canopy diameter/plant(m), average stem girth $(\mathrm{cm})$, average number of roots/plant, average length of roots/plant $(\mathrm{cm})$, average diameter of roots/plant $(\mathrm{cm})$, root fresh weight ( $\mathrm{kg} / \mathrm{plot})$, above ground biomass weight ( $\mathrm{kg} / \mathrm{plant})$ and root dry weight ( $\mathrm{kg} / \mathrm{plot})$ were recorded. Five plants were $(400 \mathrm{~g}$ each) randomly taken from the plot and were floured to get the dry matter yield of the product. After measuring the yield, the amounts are converted in to $\mathrm{kg}$ per plot.

\subsection{Statistical analysis}

Heritability in broad sense $\left(h^{2} B\right)$ and genetic advance as percent of means were calculated for all characters according to the method described by [10]. Phenotypic coefficient of variation (PCV) and genotypic coefficient of variation (GCV) were estimated according to [11] while the Mahalanobi's generalized distance $\left(D^{2}\right)$ statistics [12] was used for clustering of genotypes by assessing the divergence between genotypes for the traits measured by using SAS software statistical package [13].

\section{RESULTS AND DISCUSSION}

\subsection{Genetic Variance}

The estimates of genotypic variance, phenotypic variance, broad sense heritability, genetic advance, genetic advance in percent of means and phenotypic and genotypic coefficients of variations are presented in Table 1.

The magnitude of phenotypic variance was higher than genotypic variance as the latter is a component of the former. The phenotypic variance $\left(\sigma^{2} p\right)$ is the sum of environmental variance $\left(\sigma^{2}\right)$, genetic 
variance $\left(\sigma^{2} g\right)$ and their interaction $\left(\sigma^{2}\right.$ ge $)$. However, the phenotypic and genotypic variance values can not be used for comparing degrees of variability since different traits have different means across environments. For this reason the genotypic and phenotypic coefficients of variations were used. Comparatively, wider differences between genotypic and phenotypic coefficients of variations were observed for traits root dry weight $\mathrm{kg} / \mathrm{plot}$, weight of above ground plant parts $\mathrm{kg} / \mathrm{plant}$, canopy diameter/plant and number of vertical stem/plant while relatively narrow differences were observed were observed for traits plant height $\mathrm{cm} /$ plant, number of primary branch/plant and stem girth $(\mathrm{cm})$.

This implies that, traits showed narrow differences between genotypic coefficients of variation and respective phenotypic coefficients of variations had somewhat low sensitivity to the environmental effects while those with wider differences were affected by environmental factors.

Table 1: Estimates of Components of Variance, PCV, GCV, Heritability and Genetic Advance for 11 Quantitative Traits of Cassava Grown at Jimma. 2010/2011

\begin{tabular}{lllcllll} 
Traits & $\sigma^{2} g$ & $\sigma^{2} \mathrm{p}$ & PCV & GCV & $\begin{array}{c}\text { Heritability } \\
(\%)\end{array}$ & $\begin{array}{l}\text { Genetic } \\
\text { advance }\end{array}$ & $\begin{array}{l}\text { GAM } \\
(\%)\end{array}$ \\
PH & 931.95 & 2214.73 & 0 & 12.26 & 42.08 & 40.79 & 16.384 \\
NS & 0.028 & 0.294 & 21.98 & 6.82 & 9.52 & 0.10 & 4.362 \\
NB & 1.237 & 3.899 & 23.67 & 13.33 & 31.73 & 1.29 & 15.470 \\
CD & 55.844 & 1192.90 & 25.49 & 5.51 & 4.68 & 4.83 & 2.458 \\
GR & 0.127 & 0.651 & 28.85 & 12.76 & 19.57 & 0.32 & 11.631 \\
NoRo & 1.928 & 7.80 & 26.79 & 13.32 & 24.70 & 1.42 & 13.636 \\
LR & 6.731 & 46.99 & 18.27 & 6.91 & 14.32 & 2.02 & 5.391 \\
DR & 0.679 & 2.13 & 39.01 & 22.02 & 31.88 & 0.96 & 25.622 \\
RFW & 2562846.5 & 7885424.0 & 62.78 & 35.79 & 32.50 & 1880.0 & 42.036 \\
WAGP & 0.002 & 0.10 & 32.09 & 4.28 & 1.78 & 0.011 & 1.178 \\
RDW & 63320.0 & 1378597.62 & 54.22 & 11.62 & 4.59 & 111.01 & 5.130 \\
\hline
\end{tabular}

$\mathrm{PH}=$ Plant height, $\mathrm{NS}=$ Number of vertical stem/plant, $\mathrm{NB}=$ Number of branches/plant, $\mathrm{CD}=$ Canopy diameter, $\mathrm{GR}=$ Stem girth,

$\mathrm{NoRo}=$ number of roots/plant, LR= Length of root, $\mathrm{DR}=$ Diameter of roots, $\mathrm{RFW}=$ root fresh weight, WAGP= Weight of above plant

biomass and RDW= Root dry weight.

\subsection{Heritability}

Heritability estimates ranged from 1.78 for weight of above ground plant parts to 42.08 for plant height (Table 1). Maximum heritability was obtained for plant height, followed by root fresh weight, root diameter and number of branches per plant. Although yield is a complex character liable to have more environmental influence, heritability of root fresh weights per plot is the maximum under this study. For example, [14] found heritability of only $18.22 \%$ for tuber yield per plant in potato, which is very low as compared to the heritability obtained in this study even if the crop is different. So, further investigation could be undertaken in order to make sure such result.

Heritability indicates the ease in which a trait can be improved through selection and could vary with materials studied and environments. Therefore, varieties that are early with high fresh root yield can be developed through selection. Heritability estimates of weight of above ground plant parts, canopy diameter, root dry weight and number of vertical stem per plant were low (Table 1). Low estimate of heritability for number of tuber /hill, tuber dry weight and tuber diameter was reported in previous studies [4, 15 and 16].
High heritability coupled with high genetic advance is an important factor for predicting the resultant effect for selecting the best individuals. In the present investigation, high heritability along with high genetic advance as percent of mean was obtained for root fresh weight per plot and plant height per plant. High GCV along with high heritability and high genetic advance will provide better information than single parameters alone [17] Hence, in this study, root fresh weight per plot and plant height per plant exhibited high genotypic coefficients of variation, high heritability together with high genetic advance as percent of means. This indicates that these characters would be very useful as a base for selection in Manihot esculenta improvement programs.

\subsection{Genotype Clustering}

In this study, genotypes were grouped into five distinct clusters with different sizes. The clustering patterns of the genotypes based on quantitative characters are presented in Table 2. Cluster means of 11 quantitative traits used for clustering are presented in Table 3. A dendrogram summarizing similarity among 35 genotypes of Manihot esculenta is given in Figure 1. 
The clustering pattern indicated that the number of genotypes in each cluster varied from one in cluster IV to 15 in cluster II. Cluster I, which comprised nine genotypes (25.71\%). Genotypes in this cluster were predominantly characterized by highest number of vertical stem/plant and higher number of roots/hill (Table
2). Cluster II consisted of the maximum number of genotypes, accounting for about $42.85 \%$ of the total genotypes. Genotypes in this cluster were predominantly characterized by largest number of branch/ plant and number of roots/hill (Table 3).

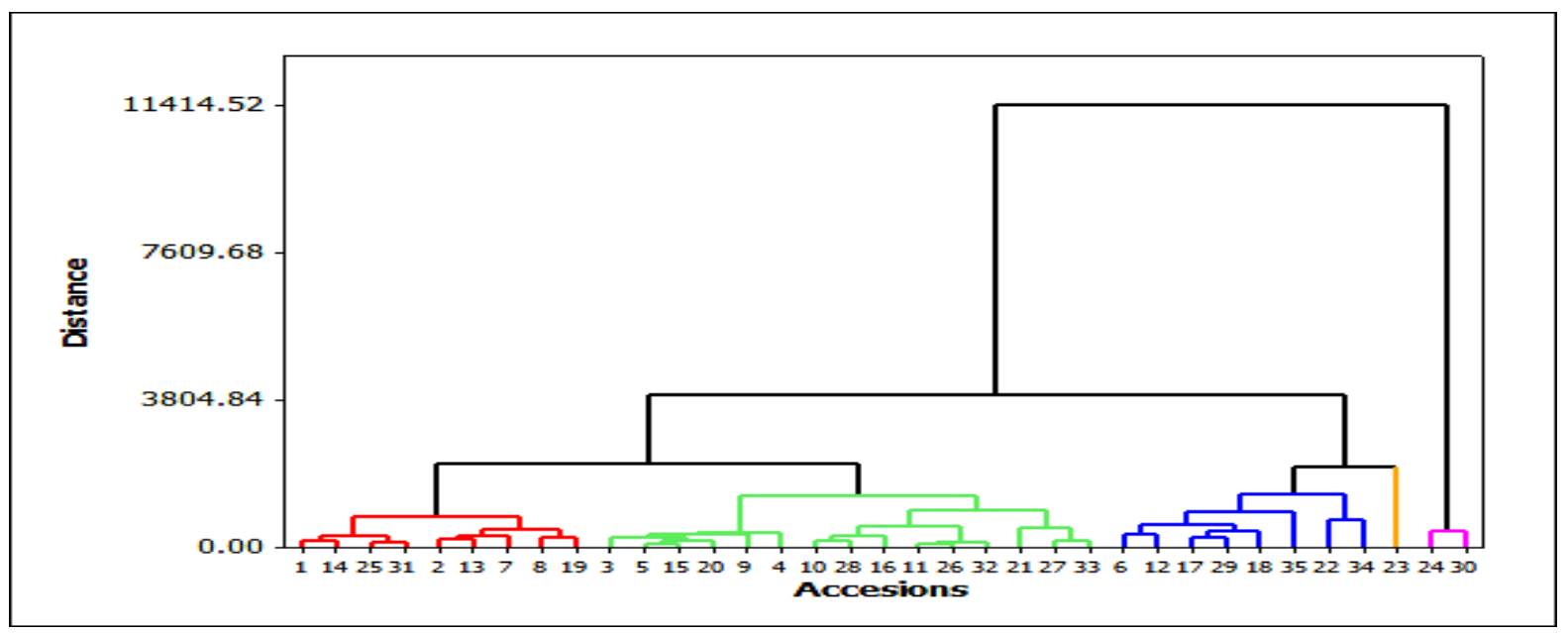

Figure 1: Dendrogram showing hierarchical clusters of 35 cassava Genotypes (UPGMA) based on quantitative characters

Cluster III had only eight genotypes $(22.85 \%)$ originally from southwest Ethiopia; it was medium performance in all parameters of quantitative traits to other clusters. For example, it has an average of $150.43 \mathrm{~cm}$ canopy diameter per plant whereas the cluster with the highest mean next to it has only $158.7 \mathrm{~cm}$ in cluster $\mathrm{V}$. The other clusters have much less number of canopy diameter (Table 12).
Cluster $\mathrm{V}$ had of two $(5.71 \%)$ genotypes originally from Jimma; it was superior in almost all parameters of quantitative traits to other clusters. For example, it has an average of $14,040.0 \mathrm{~kg}$ fresh root yield per plot whereas the cluster with the highest mean next to it has $8139.9 \mathrm{~kg}$ fresh root yield/plot in cluster IV. All other clusters have much less than cluster $\mathrm{V}$ (Table 3).

Table 2: Clusters of Manihot esculenta Genotypes Based on Quantitative Traits

\begin{tabular}{|c|c|c|c|}
\hline Clusters & $\begin{array}{l}\text { Number of genotypes in } \\
\text { each cluster }\end{array}$ & Serial number & Name of genotypes in each cluster \\
\hline I & 9 & $\begin{array}{l}1,14,25,31,2,1 \\
3,7,8,19\end{array}$ & $\begin{array}{l}\text { AAGT 108, 104/72 red, 50298-21, AAGT 194, } \\
\text { AAGT 191, 5048-33, AAGT 156, AAGT 201, and } \\
\text { AAGT } 192\end{array}$ \\
\hline II & 15 & $\begin{array}{l}3,5,15,20,9,4,1 \\
0,28,16,11,26 \\
32,21,27,33\end{array}$ & $\begin{array}{l}\text { AAGT 134, AAGT 150, 50583-14, AAGT 095, } \\
\text { AAGT 095, AAGT 189, AAGT 104, AAGT 028, } \\
45 / 72 \text { NR, 44/72 NW, 104/72 white, 45/72 NW , } \\
5648-50 \text {,Walomo and 44/72 NR }\end{array}$ \\
\hline III & 8 & $\begin{array}{l}6,12,17,29,18 \\
35,22,34\end{array}$ & $\begin{array}{l}\text { AAGT 160, 55324-4, 46330-22, AAGT 009, AAGT } \\
049,5028 / 73, \text { AAGT } 101 \text { and 50254-12 }\end{array}$ \\
\hline IV & 1 & 23 & $5538-19$ \\
\hline $\mathrm{V}$ & 2 & 24,30 & 5632-8 and AAGT 062 \\
\hline
\end{tabular}


The cluster mean of all characters is presented in (Table 3) showed that genotypes falling in cluster IV and V showed highest mean performance for all characters of interest. For example, as tuber fresh weight, tuber dry weight, weight of above ground plant parts, canopy diameter and root length. In line with this, cluster II, which consisted of 15 genotypes was the higher mean performance for the majority of quantitative characters studied (Table 3). For example, the genotypes grouped under this cluster gave the higher average number of branches/plant, stem girth, number of roots/plant, root diameter and weight of above ground plant parts.

This indicated that different clusters have different breeding values that enable breeders to improve different traits and parental selection should be made based on the relative merits of each cluster for each trait depending on the objective of the breeding program. [18] quoted by [15 and 16] further showed that while selecting genotypes from a particular cluster, the inter cluster distance; cluster mean performance should be taken into consideration.

Table 3: Mean Values of 11 Traits in 5 Clusters of 35 Cassava Genotypes Grown at Jimma 2010/2011

\begin{tabular}{llllllllllll}
\hline $\begin{array}{l}\text { Cluste } \\
\text { rs }\end{array}$ & PH & NS & NB & CD & GR & $\begin{array}{l}\text { No.R/p } \\
\text { l }\end{array}$ & RL & RDi & $\begin{array}{l}\text { RFW } \\
\text { tha }\end{array}$ & $\begin{array}{l}\text { WAG } \\
\text { Pt/ha }\end{array}$ & $\begin{array}{l}\text { RDW } \\
\text { t/ha }\end{array}$ \\
\hline I & 181.1 & 2.86 & 8.32 & 122.28 & 2.09 & 11.20 & 34.03 & 2.18 & 1606.5 & 0.59 & 610.00 \\
II & 240.6 & 2.66 & 8.85 & 141.70 & 2.56 & 12.15 & 37.28 & 3.25 & 3547.0 & 0.98 & 1520.4 \\
III & 268.9 & 2.52 & 7.41 & 150.43 & 2.87 & 10.05 & 43.22 & 4.16 & 6161.1 & 0.88 & 2681.4 \\
IV & 310.0 & 2.13 & 6.25 & 149.25 & 2.75 & 10.22 & 42.40 & 3.83 & 8139.9 & 1.34 & 3182.4 \\
V & 267.2 & 2.10 & 5.70 & 158.7 & 3.50 & 12.80 & 50.60 & 7.70 & 14040. & 1.4 & 6618.8 \\
& & & & & & & & & 0 & & \\
\hline
\end{tabular}

$\mathrm{PH}=$ Plant height $(\mathrm{cm}), \mathrm{NS}=$ Number of vertical stem/plant, $\mathrm{NB}=$ Number of branches/plant, $\mathrm{CD}=\mathrm{Canopy}$ diameter $(\mathrm{cm}), \mathrm{GR}=\mathrm{Stem}$ girth $(\mathrm{cm}), \mathrm{NoRo}=$ number of roots/plant, $\mathrm{RL}=\mathrm{Root}$ length $(\mathrm{cm}), \mathrm{RDi}=\mathrm{Root}$ Diameter(cm), RFW= root fresh weight(t/ha), WAGPP = Weight of above plant biomass (t/ha) and RW= Root dry weight(t/ha).

The pair wise generalized square distances $\left(D^{2}\right)$ between the clusters (Table 4) showed that the distance between most of the clusters were highly significant $(\mathrm{P}<$ 0.01 ) suggesting diversity among Genotypes in different clusters. The maximum inter-cluster distance $\left(D^{2}=\right.$ 13809.60) was noticed between cluster I and $V$ followed by II and V $\left(D^{2}=11666.10\right)$ and II and IV $\left(D^{2}=4884.73\right)$ suggesting diversity between these groups. 
Table 4: Pair Wise Generalized Squared Distances Between five Clusters of Manihot esculenta

\begin{tabular}{llllll}
\hline Cluster & Cluster I & Cluster II & Cluster III & Cluster-IV & Cluster- V \\
\hline I & 0.0 & $2144.4^{\star *}$ & $5004.38^{\star *}$ & $7022.64^{\star *}$ & $13809.60^{\star *}$ \\
II & & 0.00 & $2860.50^{\star *}$ & $4884.73^{\star \star}$ & $11666.10^{\star *}$ \\
III & & & 0.00 & $2041.45^{\star \star}$ & $8807.90^{\star *}$ \\
IV & & & 0.00 & $6828.0^{\star *}$ \\
V & & & & 0.0 \\
\hline
\end{tabular}

${ }^{*}=$ Significant at 0.05 probability level $\left(x^{2}{ }_{10}=18.31\right)$

$* *=$ Highly significant at 0.01 probability level $\left(x^{2}{ }_{10}=23.21\right)$

Hence, inter-mating between genotypes included in these clusters may give high heterotic response and thereby better sergeants in view of the genetic diversity. For instance, in this study, based on their tuber yield, selecting and crossing genotypes AAGT 108 (serial number1) from cluster I with genotypes 5632-8 (serial number 24) from cluster $V$ and AAGT 150 (serial number 5) from cluster II with genotypes 30 from cluster $V$ (Table 2) may produce desirable recombinants for high tuber fresh weight. However, in this study, there is no cluster that have low inter cluster distance (Table 2). Intensive selection for agronomically important characters and similarity in parentage might be the cause of narrow genetic diversity and uniformity between these clusters. However, [19] quoted by [4] and [14] indicated that, selection of parents should also consider the special merits of each cluster and each genotype within a cluster depending on the specific objective of hybridizations.

In this study there was no clear grouping of the genotypes according to regions of collection. Genotypes of one region were classified into different clusters although some of them also belonged to the same cluster. Genotypes collected from different regions were also grouped into the same cluster. Therefore, it may be of considerable importance to enlarge the genetic base of Mainhot esculenta by sustainable and continual collection of genotypes throughout the growing areas of the country, conduct genetic improvement work to exploit desirable traits of the genotypes.

\section{CONCLUSIONS}

In this study, root fresh weight showed moderately heritability associated with higher genetic advance and higher genetic advance as means of percentage indicates the better chance of selection for varieties with high fresh root yield than those traits with moderate heritability but having low genetic advance such as weight of above ground plant parts, number of vertical stem/plant and diameter of root. The higher genetic distance observed in this study indicates the potential of improving root fresh yield of cassava by crossing those parents shows higher genetic distance which can yield hetrosis.

\section{ACKNOWLEDGMENTS}

The Author like to acknowledge Jimma Agricultural Research Centre for the financial support and Dr. Hussein Mohammed, Awassa University, College of Agriculture for technical edition and sharing his valuable comments.

\section{REFERENCES}

Tewodros Mulualem. (2012). Production, Storage and Post- harvest Utilization System of Cassava, Lambert Acadamic Publishing. Saarbrucken, Germany.

Nweke , F. I and Enete, A.A. (1999). Gender Surprise in Food Production, Processing and Marketing with Emphasis on Cassava in Africa,. Volume 19: Collaborative Study on Cassava in Africa, IITA, Ibadan, Nigeria.

Tewodros Mulualem, (2012). Genetic Variability of Cassava in Ethiopia, Lambert Acadamic Publishing. aarbrucken, Germany.

Amsalu, Nebiyu. (2003). Characterization and Divergence Analysis in Cassava (Manihot esculenta Cranz) Genotypes at Jimma. MSc thesis, Alemaya University, Ethiopia. Central Statistics Authority (CSA (2003/2004).) Report on Agricultural Production and Land Utilization, Statistical Bulletin 302. AA, Ethiopia.

Edossa Etissa. (1996). Root and Tuber Crops:" Potential as Food Crops in the Humid Areas of Ethiopia". Institute of Agricultural Research, pp 2.

Onwueme, I.C. and Charles, W.B.. (1994). Tropical Root Crops: Yams, Cassava, Sweet potato and Cocoyams. Jhon Wiley and Sons LTD., Chichester, USA, pp 243. 
Edwards, Sue. (1991). Crops with Wild Relatives Found in Ethiopia. In: Engels, J.M.M, Hawkes J.G. and Melaku Worede (ed): Plant Genetic Resource of Ethiopia. Cambridge..

Tewodros Mulualem and Biruk Ayenew. (2012). Cassava (Mannihot esculenta Cranz) Varieties and Harvesting Stages Influenced Yield and Yield Related Components, International Institute of Science and technology, pp, 4-6.

Johonson, H.W., H.F. Robinson and R.E. Comostock. (1955a.). Estimates of Genetics and Environmental Variability in Soybeans Agron. J. 47, 314-318,

Burton, G.W and Dewane, E.M. (1997). Estimating Heritability in Tall Fesue (Fistula arundanaceae) from Replicated Clonal Material. Agron J. 48: 478481, 1951.IPGRI/IITA, International Plant Genetic Resources Institute/International Institute for Tropical Agriculture, Descriptors for Taro (Collocasia spp.)., Ibadan, Nigeria, Rome, Italy.

Bhatt, G.M., (1970). Multivariate Analysis Approach to Selection of Parents for Hybridization Aiming Yield Improvement in Self Pollinated Crops, Aust. J. agric. Res., 21:1-7. SAS, (1999). Statistical Analytical Systems SAS / STAT User's Guide Version 8(2) cary NC :SAS Institute inc..
Baye, B., Ravishankar, R. and Singh, H. (2005). Variability and Association of Tuber Yield and Yield Related Traits in Potato, Eth. J. Agric. Science, 18, 103-121.

Woyessa Garedew. (2006)Morphological Characterization and Divergence Analysis of Plectranthus edulis (Vatke) Agnew Collection in Ethiopia. M.Sc. thesis, Hawassa University, Ethiopia.

Asfaw, K. (2006). Characterization and Divergence Analysis of Some Ethiopian Taro (Collocasia esculenta (L.) Genotypes M.Sc thesis, Alemaya University, Ethiopia.

Saha, S. C., Mishira, S. N. and Mishira, R.S. (1990). Genetic Variation in $F_{2}$ Generation of Chilli Capsicum News Letter, 8, 29-30.

Dewey, D.R. and Lu, K. H.. (1959). Correlation and Path Coefficients Analysis of Components of Crested Wheat Grass Seed Production. Agron. J., 51:515518.

Gemechu, K., Belay, S., and Getinet, G. (1997). Genetic Diversity of Groundnut Germplasm in Ethiopia, Ethiopia J. Agric. Sci. 16: 1-12. 